EESTI NSV TEADUSTE AKADEEMIA TOIMETISED. KEEMIA ИЗВЕСТИЯ АКАДЕМИИ НАУК ЭСТОНСКОИ ССР. ХИМИЯ PROCEEDINGS OF THE ACADEMY OF SCIENCES OF THE ESTONIAN SSR. CHEMISTRY

$1988,37,1$

УДК $661.183 .1: 661.185: 543.24$

Татьяна ЛИИВ, И. КУДРЯВЦЕВ

\title{
ОПРЕДЕЛЕНИЕ СРЕДНЕЙ МОЛЕКУЛЯРНОЙ МАССЫ АНИОННЫХ ПОВЕРХНОСТНО-АКТИВНЫХ ВЕЩЕСТВ В ПРИСУТСТВИИ НЕОРГАНИЧЕСКИХ СОЛЕЙ
}

\author{
(Представил И. Клесмент)
}

Среднюю молекулярную массу анионных пेоверхностно-активных веществ (АПАВ) определяют по методике, разработанной во ВНИИ жиров ['], с применением отечественной катионообменной смолы КУ-2. Согласно этой методике, исследуемое вещество должно быть тщательно очищено от минеральных солей, присутствие которых снижает истинную среднюю молекулярную массу АПАВ. Однако добиться такой степени очистки можно только многократной перекристаллизацией при помощи абсолютного спирта, а это процесс весьма сложный и на практике трудноосуществимый. Обычно в моющих веществах содержатся минеральные соли, которые при экстракции АПАВ 96\%-ным этиловым спиртом частично переходят в раствор ['].

При синтезе алкенилсульфоната (АС) в реакционной смеси содержатся также сульфит, сульфат и хлорид натрия, присутствие которых мешает определению истинной средней молекулярной массы АС.

Нами разработана методика определения истинной средней молекулярной массы АПАВ в присутствии вышеупомянутых минеральных солей, содержание которых в смеси может достигать $10-15 \%$, без предварительной экстракции 96\%-ным этиловым спиртом.

Кроме того, предлагаемая методика предусматривает параллельное проведение химического анализа минеральных солей объемными методами, данные которых учитываются при расчете истинной средней молекулярной массы АПАВ.

\section{Методика}

Раствор искусственной композиции с известным содержанием минеральных солей и собственно АС пропускали через колонку с катионообменной смолой КУ-2 [1] и собранный фильтрат титровали 0,1 н. раствором щелочи. В растворе композиции параллельно определяли содержание минеральных солей объемными методами. Хлорид натрия определяли аргентометрическим потенциометрическим титрованием галоидов $\left[{ }^{2}\right]$, сульфит натрия - иодометрически [3], сульфат натрия - титрованием нитратом бария в присутствии индикатора хлорфосфоназо III [ $\left.{ }^{4}\right]$.

Объем щелочи, израсходованный на нейтрализацию минеральных кислот, которые образуются при прохождении раствора композиции через катионообменную смолу, определяли по формуле

$$
c n_{1}=d \cdot n_{2},
$$

где $c$ - объем титрованного раствора, израсходованный на анализ соли, мл; $n_{1}$ и $n_{2}$ - нормальность титрованного раствора и раствора щелочи соответственно; $d$ - рассчитанный объем 0,1 н. раствора едкого натра, соответствующий содержанию минеральных солей в навеске, мл. 
Истинную среднюю молекулярную массу вычисляли по формуле

$$
M=\frac{a \cdot m \cdot 1000}{(b-d) \cdot K},
$$

где $a-$ навеска испытуемого вещества, г; $m-$ доля АС в навеске; $b-$ общий объем 0,1 н. раствора едкого натра, израсходованный на титрование фильтрата, мл; $K-$ коэффициент поправки к нормальности раствора едкого натра.

Для проверки «работоспособности» предложенной методики анализировали растворы отдельных компонентов минеральных солей и собственно АС. Параллельно растворы пропускали через колонки с катионитом КУ-2 ['].

\section{Экспериментальная часть}

Приготовление раствора. Растворы готовили в мерных колбах на 250 мл, используя в качестве растворителя $50 \%$-ный этиловый спирт. АС многократно перекристаллизовывали из спирта. Для приготовления раствора искусственной композиции брали 1,3171 г АC $(86,2 \%), 0,0325$ г хлорида натрия $(2,13 \%), 0,05905$ г сульфата натрия $(3,86 \%), 0,1193$ г сульфита натрия $(7,81 \%)$, общая навеска композиции составила 1,52795 г. Готовили растворы собственно АС и минеральных солей в отдельности с тем же содержанием компонентов, что и в растворе композиции.

Определение средней молекулярной массы по методике [']. 25 мл раствора композиции пропускали через колонку с катионитом КУ-2 и затем трижды промывали спиртом по 25 мл до нейтральной реакции среды фильтрата. Объединенный фильтрат титровали 0,1 н. раствором едкого натра в присутствии $4-5$ капель метилового красного до желтой окраски раствора. Расход щелочи составнл 7,92 мл, средняя молекулярная масса АС при этом была равна

$$
M=\frac{1,52795 \cdot 1000}{7,92 \cdot 1,01}=191 .
$$

При анализе раствора, содержащего АС, были получены следующие данные: расход щелочи составил 4,625 мл, при этом истинная средняя молекулярная масса равнялась 282 . В растворе композиции определяли содержание хлорида, сульфита и сульфата натрия.

Определение хлорида натрия [ㄹ. К 25 мл исследуемого раствора композиции доливали 50 мл ацетона и 2 мл азотной кислоты и титровали 0,01 н. раствором нитрата серебра. Конец титрования определяли потенциометрически.

Расход нитрата серебра составил 5,6 мл. Содержание хлорида натрия:

$$
\mathrm{NaCl}=\frac{58,5 \cdot 0,0098 \cdot 5,6}{152,795} \cdot 100=2,1 \% .
$$

Объем щелочи, соответствующий найденному содержанию хлорида натрия, равен:

$$
d_{1}=\frac{5,6 \cdot 0,0098}{0,101}=0,543 \text { мл. }
$$

Определение сульфата натрия [4]. К 5 мл испытуемого раствора доливали 0,25 мл 2 н. раствора соляной кислоты и 25 мл ацетона и титровали 0,02 н. раствором нитрата бария в присутствии двух капель $0,2 \%$-ного 
раствора хлорфосфоназо III до перехода фиолетово-розовой окраски в сине-голубую.

Расход нитрата бария на 5 мл раствора составил 0,81 мл. Содержание сульфата натрия:

$$
\mathrm{Na}_{2} \mathrm{SO}_{4}=\frac{71,025 \cdot 0,02 \cdot 0,81 \cdot 250}{1527 \cdot 95 \cdot 5} \cdot 100=3,76 \%
$$

Объем щелочи:

$$
d_{2}=\frac{0,81 \cdot 0,002 \cdot 5}{0,101}=0,802 \text { мл. }
$$

Определение сульфита натрия [3]. К 25 мл испытуемого раствора доливали 20 мл 0,1 н. раствора иода и ставили в темное место; через несколько минут избыток иода оттитровывали 0,1 н. раствором тиосульфата натрия, добавляя в конце титрования раствор крахмала.

Расход тиосульфата натрия составил 1,89 мл. Содержание сульфита натрия:

$$
\mathrm{Na}_{2} \mathrm{SO}_{3}=\frac{6,3 \cdot 0,1 \cdot 1,89 \cdot 0,99}{0,152795}=7,71 \%
$$

Объем щелочи:

$$
d_{3}=\frac{1,89 \cdot 0,099}{0,101}=1,853 \text { мл. }
$$

Общее содержание солей в навеске композиции равно $13,57 \%$. Содержание АC - 86,43\% .

Общий объем щелочи, соответствующий содержанию солей в навеске, - 3,2 мл. Расход щелочи, соответствующий собственно АС в навеске композиции, равен

$$
7,92-3,2=4,72 \text { мл. }
$$

Средняя молекулярная масса АС с учетом полученных данных:

$$
M=\frac{1,52795 \cdot 0,8643 \cdot 1000}{4,72 \cdot 1,01}=277,
$$

т. е. отличается от найденной на 5 ед.

Определение расхода щелочи на минеральные кислоты. Растворы последних пропускали через колонку с катионитом КУ-2 [']. При нейтрализации фильтрата расход щелочи составляет:

для 25 мл раствора хлорида натрия $-0,55$ мл,

для 25 мл раствора сульфата натрия - 0,825 мл,

для 25 мл раствора сульфита натрия - 1,875 мл, что в сумме дает 3,25 мл, отклонение от расчетного - $1,54 \%$.

Расход щелочи на алкенилсульфокислоту:

$$
7,92-3,25=4,67 \text { мл, }
$$

т. е. отличается от экспериментально полученной при анализе раствора AC на $0,96 \%$.

Средняя молекулярная масса с учетом загруженной навески $\mathrm{AC}$ :

$$
M=\frac{1,3171 \cdot 1000}{4,67 \cdot 1,01}=279
$$

т. е. отличается от найденной на 3 ед.

Сравнение значений $\mathrm{M}$ для $\mathrm{AC}$, очищенного от солей и в композиции с ними, показывает, что с помощью предлагаемой методики определяется 
истинная средняя молекулярная масса $\mathrm{AC}(\mathrm{M}=277)$ в присутствии минеральных солей, отличающаяся от эталонной $(M=282)$ на 5 ед., т.е. на $1,8 \%$. Наличие в продукте $13,57 \%$ минеральных солей снижает значение средней молекулярной массы АС на $42 \% \quad(M=191)$.

Предлагаемая методика позволяет исключить из анализа такой этап, как испарение соляной кислоты, образующейся из хлористого натрия вследствие обмена на смоле КУ-2 иона натрия на ион водорода.

\section{Выводы}

1. Разработана методика определения средней молекулярной массы АПАВ в присутствии неорганических солей.

2. Проведение предварительных объемных анализов отдельных компонентов неорганических солей позволяет рассчитать поправку для расчета истинной средней молекулярной массы АПАВ.

3. Выбранные методы объемного анализа отдельных компонентов неорганических солей не перекрывают друг друга и позволяют провести селективный анализ.

4. Предлагаемая методика позволяет обойтись без предварительной экстракции АПАВ 96\%-ным этиловым спиртом, а также исключить из анализа испарение соляной кислоты, образующейся из хлористого натрия вследствие ионного обмена на смоле КУ-2.

5. «Работоспособность» методики опробована при наличии в смеси АПАВ сульфита, сульфата и хлорида натрия.

\section{Л И ТЕ Р А Т Р А}

1. Неволин Ф. В. Химия и технология синтетических моющих средств. М., 1971, $338-343$.

2. Климова В. А., Виталина М. Д. Потенциометрическое микротитрование галоидов в органических соединениях после их минерализации. - Ж. аналит. хим., 1960, 15, $339-341$.

3. Алексеев В. Н. Количественный анализ. М., 1963, 416; Шарло Г. Методы аналитической химин. Количественный анализ неорганических соединений, II. М., 1969 , $1000-1001$.

4. Лукин А. М., Чернышева T. В. Объемное определение сульфатов с хлорфосфоназо III. - Заводск. лаборатория, 1968, 34, № 9, 1054-1056.

\section{Институт химии \\ Академии наук Эстонской ССР \\ Поступила в редакцию \\ 20/I 1987 \\ Tatjana LIIV, I. KUDRJAVTSEV \\ ANIOONSETE PINDAKTIIVSETE AINETE KESKMISE MOLEKULMASSI MÄARAMINE ANORGAANILISTE SOOLADE MANULUSEL}

On välja töötatud meetod anioonsete pindaktiivsete ainete keskmise molekulmassi määramiseks anorgaaniliste soolade manulusel. Soolade sisaldus on eelnevalt määratud mahtanalüüsi meetodil. Uut meetodit on kontrollitud naatriumsulfiti, -sulfaadi ja -kloriidi segu manulusel.

\section{Tatyana LIIV, I. KUDRYAVTSEV}

\section{DETERMINATION OF AVERAGE MOLECULAR MASS OF ANIONIC SURFACTANTS IN THE PRESENCE OF INORGANIC SALTS}

A method for determining average molecular mass of anionic surfactants in the presence of inorganic salts has been developed. The content of the latter has been previously determined by the method of volumetric analysis. The method suggested has been verified in the presence of a mixture of sodium sulfite, sulfate and chloride. 